\title{
EROSION AND MECHANICAL PROPERTIES OF HYDROTHERMALLY- RESISTANT NANOSTRUCTURED ZIRCONIA COMPONENTS
}

Sina Saremi-Yarahmadi ${ }^{1}$, Jon Binner ${ }^{2}$, Bala Vaidhyanathan ${ }^{1 *}$

\begin{abstract}
Large scale 50×50 mm sintered nanostructured zirconia ceramics were fabricated via industrially viable dry pressing routes. The green bodies were sintered by a two-stage process and the optimised sintering conditions are reported. The suitability of nanostructured zirconia for demanding applications in petrochemical valve components was investigated by slurry impingement erosion experiments. Zirconia showed a 60-fold improvement compared to commonly used stellite-coated commercial stainless steel specimens under test conditions while no tetragonal to monoclinic phase transformation was observed after erosion. The enhanced performance was also valid when compared with reported erosion resistant properties of alumina and zirconia components by a factor of 36 and 3, respectively. This suggests nanostructured zirconia as a potential robust alternative material for construction of internal trim components of petrochemical valves.
\end{abstract}

\footnotetext{
${ }^{1}$ Department of Materials, Loughborough University, Loughborough, LE11 3TU, UK

* Corresponding author, Permanent address: B.Vaidhyanathan@lboro.ac.uk, Telephone (+44) 01509223152

${ }^{2}$ College of Engineering and Physical Sciences, University of Birmingham, Edgbaston, Birmingham, B15 2TT, UK.
} 
Keywords: Pressing, Sintering, Nanostructured Zirconia, Slurry Erosion, Hydrothermal Ageing

\section{Introduction}

Nanocrystalline materials are attractive choices for many applications as they offer unprecedented properties leading to development of new products with improved performance [1]. Nanostructured ceramics are a class of nanomaterials with average grain sizes less than $100 \mathrm{~nm}$ which offer many advantages in a variety of applications. For example, one of the major advantages of using nanoceramics includes lower sintering temperature which could enable co-sintering with metals for applications such as solid oxide fuel cells (SOFCs)[2]. Nanoceramics are also expected to yield better mechanical, thermal and physical properties.[1] For example, nanoceramic cutting tools have been reported to be harder and yet more ductile [3].

Zirconia-based ceramics are known to yield excellent toughness, hardness, wear resistance, strength and ionic conductivity and so are used in a wide range of engineering applications from wear parts for the die drawing industry through to oxygen sensors and solid oxide fuel cells [4-6]. The superior wear resistance properties of these types of engineering ceramics make them suitable materials for applications where erosion and wear is a problem for conventional metallic materials, such as in pumps and valve in slurry transport pipelines and petrochemical valves [7-10]. 
One major limitation for these ceramics, however, is their lack of resistance to a process known as hydrothermal ageing (HTA)[11]. Recently, Binner et al.[12] fabricated nanostructured zirconia components which very significantly outperformed the conventional submicron zirconia in terms of resistance to HTA. This was a step change in manufacturing zirconia which would widen the application of nanostructured zirconia to products that need a hydrothermally resistant grade, for example, surgical tools, implant materials (e.g. hip joint and dental replacements) and internal trim components and wear parts for valves and pumps for use in the petrochemical industry.

This paper reports recent developments in the manufacture of large components of nanostructured zirconia fabricated through dry pressing routes. Furthermore, it presents the results of the mechanical and slurry erosion properties of such components with the view of investigating the potential application of nanostructured zirconia in petrochemical valve components. The findings show that nanostructured zirconia performed better than conventional stainless steel materials used in such applications. This suggests that nanostructured zirconia has the potential to be used as a robust alternative material in construction of internal trim components of petrochemical valves.

\section{Experimental}

Concentration of nanosuspensions - Zirconia nanosuspensions containing $3 \mathrm{~mol} \%$ yttria were provided by MEL Chemicals, UK; the solids content of the as-received nanosuspension was $24 \mathrm{wt} \%$. These were concentrated to up to $55 \mathrm{wt} \%$ solids content using a thermally-assisted patented route developed at Loughborough University. The details of the processing route are given elsewhere [13,14]. Briefly, it involves 
modifying the $\mathrm{pH}$ of the nanosuspension to 11.5 via the addition of sufficient quantities of tetramethyl ammonium hydroxide (TMAH, Aldrich Chemicals Ltd., Dorset, UK), followed by the addition of $3 \mathrm{wt} \%$ tri-ammonium citrate (TAC, Fisher Scientific UK Ltd., Loughborough, UK) as a dispersant. The final concentrated suspension with solids content of $55 \mathrm{wt} \%$ was obtained by heating the suspension to $65^{\circ} \mathrm{C}$ under continuous stirring to evaporate water and frequent ultrasound treatment using a Soniprep 150 ultrasonicator (MSE scientific instruments, Manchester, UK) to break the agglomerates.

Powder production - The granulated powder suitable for dry pressing was obtained by spray freeze drying of concentrated nanosuspension as detailed by Zhang et al.[15] In order to obtain flowable and crushable granules, 2 wt\% Freon 11 (flurotrichloromethane; Fisher Scientific U.K.) was added to the concentrated nanosuspension prior to spraying[16]. The spray nozzle used was a twin-fluid atomiser where air was used as carrier gas. The nanosuspension was sprayed into a nitrogen bath and the powder immersed in the nitrogen was then dried using a VirTis Benchtop 2K freeze dryer (SP Industries, Gardiner, NY). The frozen granules transferred to the vacuum dryer were dried via sublimation of the water, which completed in about 48 hours. After drying, the powders were sieved to extract the fraction between 125 and $250 \mu \mathrm{m}$ (to maximize flowability) and then heat treated at $70^{\circ} \mathrm{C}$ for $1 \mathrm{~h}$ to burn off the Freon.

Green body formation - Green rectangular compacts of two different sizes of $45 \times 25$ $\mathrm{mm}$ and $65 \times 65 \mathrm{~mm}$ were dry pressed in two stages. The former were used for mechanical testing whilst the latter was used in slurry erosion experiments. In the initial stage, the green compacts were dry pressed in a single-action, hardened steel die at a consolidation pressure of $110 \mathrm{MPa}$, followed by isopressing at a consolidation pressure of $200 \mathrm{MPa}$ for $1 \mathrm{~min}$ using in-house, vacuum sealed plastic wet bags. $5 \mathrm{~g}$ of powder 
was used to fabricate smaller tiles whilst $80 \mathrm{~g}$ of powder was used to manufacture tiles for erosion testing. The tiles were then removed from the wet bags and used for further processing.

The organic additives (TMAH and TAC) which were added during the concentration stages were removed during a slow heating cycle (heating rate of $0.5^{\circ} \mathrm{C}$ per minute) comprising of holding at $100^{\circ} \mathrm{C}, 200^{\circ} \mathrm{C}, 300^{\circ} \mathrm{C}$ and $400^{\circ} \mathrm{C}$ for 30 min each and finally at $700^{\circ} \mathrm{C}$ for $2 \mathrm{~h}$. The samples were then cooled down to room temperature using a cooling rate of $0.5^{\circ} \mathrm{C}$ per minute. The green density of the dry pressed tiles was calculated from the weight of the tile and its geometrical dimensions. The dimensions were measured at three locations across the sample and averaged out for calculations.

Densification and sintering - Sintering of the tiles was carried out using a conventional box furnace (Carbolite UK Ltd.). The green bodies were sintered using a two-step sintering cycle where the samples were heated to a high initial temperature, known as T1, held at this temperature for a very short period of time (6 s), before being cooled down to a lower temperature, known as T2. T1 was varied from $1400^{\circ} \mathrm{C}$ to $1250^{\circ} \mathrm{C}$ whilst T2 was selected from $1300^{\circ} \mathrm{C}$ to $1150^{\circ} \mathrm{C}$ accordingly. The samples were held for at $\mathrm{T} 2$ for different lengths of time (1.5 to $10 \mathrm{hrs}$ ) so that complete densification was achieved. Grain size and density of the sintered samples were used as indicators to specify the best sintering conditions. The density of the sintered samples was measured using the Archimedes principle with distilled water as the displacing medium and utilizing the proper density correction for the temperature of the medium. The average grain size of the samples were analysed using a Leo 1530VP field emission gun scanning electron microscope (Leo 1530VP FEGSEM, LEO Elektronenskopie GmbH, Oberkochen, Germany) at different magnifications. The grain size was determined using 
the linear intercept method (ASTM E 112-96). The two dimensional grain size was converted to three dimensional using a conversion factor of 1.56 [17].

Mechanical properties - The Vickers micro indentation hardness of the samples was determined as per ASTM E 384, using a Mitutoyo HM-124 micro hardness tester (Mitutoyo Corporation, Kawasaki, Japan) and by applying a load of $1 \mathrm{~kg}$ for $15 \mathrm{~s}$. The indentation toughness of the samples was determined using a Mitutoyo AVK-C2 hardness tester (Mitutoyo Corporation, Kawasaki, Japan). The indents on the samples were created using a Vickers pyramidal indenter by applying a $10 \mathrm{~kg}$ load for $15 \mathrm{sec}$ (Young's modulus used in calculations $=210 \mathrm{GPa}$ ). The flexural strength of the different samples were determined according to ASTM C 1161-02c for size A specimens. The inner span was $20 \mathrm{~mm}$. The samples were cut and ground into rectangular section test-pieces measuring $1.5 \mathrm{~mm} \times 2 \mathrm{~mm} \times 25 \mathrm{~mm}$. The sample bars were tested in a 3-point bending test configuration using an Instron 4505 machine with United Kingdom Accreditation Service (UKAS) accredited load cell calibration at a cross-head displacement rate of $0.2 \mathrm{~mm} \mathrm{~min}^{-1}$.

Slurry jet impingement erosion test - Slurry erosion experiments were carried out to evaluate the performance of the nanostructured zirconia ceramics under slurry erosion conditions in order to establish their suitability in aggressive conditions. The performance of the ceramic materials was benchmarked against that of a wear-resistant (316) stainless steel coated with a stellite 6 overlay, which is commonly used in such aggressive environments. The samples were tiles of $50 \times 50 \mathrm{~mm}$ with a thickness of $\sim 5$ $\mathrm{mm}$. The test rig consisted of a pump that pushed the slurry to the test chamber. The details of the rig design are reported elsewhere [8]. The tile samples were weighed 3 times and then placed onto the sample holder and the erosion chamber was closed and 
sealed properly. The slurry erosion test was carried out according to the following procedure using the test conditions as of Table 1 :

Table 1. Slurry jet impingement test conditions.

\begin{tabular}{cccccc} 
Flow rate & Jet velocity & Nozzle & Sand size & Test time & Impact \\
$/ 1 \cdot \mathrm{min}^{-1}$ & $/ \mathrm{m} \mathrm{s}^{-1}$ & diameter & $/ \mu \mathrm{m}$ & $/ \mathrm{min}$ & angle \\
& & $/ \mathrm{mm}$ & & & 10 \\
\hline 35 & 21.8 & 6 & $180-250$ & 90 & 90
\end{tabular}

The rig was flushed and emptied. It was then filled with 9 litres of tap water. An appropriate mass of dry sand (erodent) was added to the flowing water to ensure an even distribution of the sand particles and slurry consistency to yield a slurry concentration of $2.1 \mathrm{wt} \%$. The sample was then secured in the holder at an impingement angle of $90^{\circ}$. The flow rate was set to $35 \mathrm{l} \cdot \mathrm{min}^{-1}$. Each test was run for 90 minutes. The samples were removed, cleaned using running water, dried and weighed using a precision mass balance to an accuracy of $\pm 0.02 \mathrm{mg}$.

Surface characterisation - The erosion wear crater and surface roughness of the samples were measured using a Talysurf CLI 2000 system (Taylor Hobson UK Ltd.). The measurements were carried out in noncontact mode using a CLA 3000 induction gauge. From a 2D map of a $25 \times 25 \mathrm{~mm}$ representative area, line profiles were generated to calculate the average surface roughness parameter.

Micro-Raman analysis (LabramHR spectrometer, Horiba Jobin Yvon, Villeneuve d'Ascq, France), wavelength $632.8 \mathrm{~nm}$, was performed to map qualitatively the different phases present at the surface of the samples before and after the erosion 
experiments. An average of two spectra was taken from every data point and the spectra were recorded from 100 to $800 \mathrm{~cm}^{-1}$.

\section{Results and Discussions}

Green forming and optimisation of sintering conditions - Figure 1 shows the changes in the dimensions of the samples after binder removal and sintering. As shown, the green compacts did not achieve high green densities resulting in only $42 \%$ theoretical density (TD) after uniaxial pressing at $110 \mathrm{MPa}$. However, the green density was increased 52\% after isopressing and binder removal.

The temperature-time regimes for obtaining nanostructured zirconia components via a wet processing route have already been reported. Binner et al. [12] reported that slip cast bodies of 3YSZ reached densities of $99.5 \%$ of the theoretical density (TD $=6.05 \mathrm{~g}$ $\mathrm{cm}^{-3}$ ) and a final mean grain size of $\sim 65 \mathrm{~nm}$ using a two stage sintering approach (sintering conditions: $6 \mathrm{~s}$ at $1150^{\circ} \mathrm{C}(\mathrm{T} 1)$ followed by $3 \mathrm{~h}$ at $1050^{\circ} \mathrm{C}(\mathrm{T} 2)$ ). However, it was observed that the die-pressed samples prepared from spray freeze dried granules could not be densified to high densities when sintered at temperatures below $1150{ }^{\circ} \mathrm{C}$. Similar heating profiles resulted in a sintered density of $\sim 92 \%$ of TD, which was not acceptable. This was attributed to the lower green compact densities achieved ( 52\% of TD) for dry pressed samples at $200 \mathrm{MPa}$, hence higher sintering temperatures were required to obtain maximum densification. This, in turn, made it more difficult to maintain the nanostructure at less than $100 \mathrm{~nm}$. Therefore, priority was given to obtaining higher sintered densities and temperature-time profiles of sintering were selected accordingly. This decision was governed by the fact that the mechanical 
strength of the component would be strongly affected by the final density of the sintered body. Nevertheless, the sintering profile was carefully chosen so that it would result in the smallest grain size possible at high sintered densities.

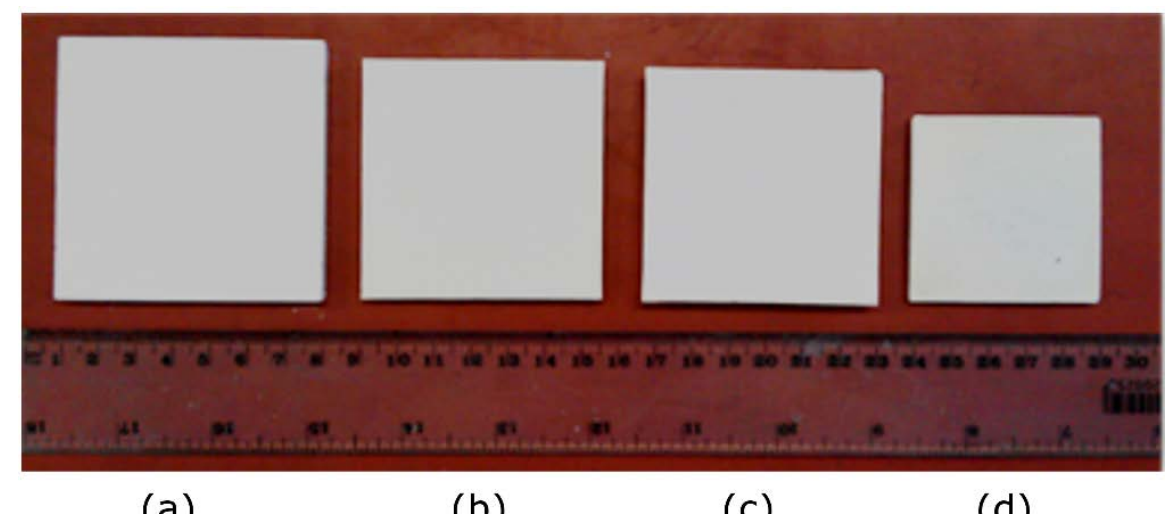

(a)

(b)

(c)

(d)

Figure 1. Pictures of samples as-pressed and after every processing step. (a) green compact after dry pressing at $110 \mathrm{MPa}$, green density of 42.5\% TD, (b) green compact after isopressing at $200 \mathrm{MPa}$, green density of 49\%TD, (c) green compact after binder removal, green density of 52\%TD and (d) sintered sample with density of 98.2\%TD.

The density and grain sizes obtained after two stage sintering at relevant T1 and T2 are given in Table 2 . These results confirmed that densities of $>98 \%$ TD were achieved by selecting a $\mathrm{T} 2$ as low as $1250^{\circ} \mathrm{C}$ and heating rate of $5^{\circ} \mathrm{C} \mathrm{min}^{-1}$. However, it was observed that the green density of large $65 \times 65 \mathrm{~mm}$ tiles was approx. 2-3 \% lower than that of the $45 \times 25 \mathrm{~mm}$ tiles. As a result, to obtain similar sintered densities for large tiles it was necessary that sintering experiments were carried out at higher temperatures and for longer times, i.e. $1400^{\circ} \mathrm{C}$ for $\mathrm{T} 1$ and $1300^{\circ} \mathrm{C}$ for $\mathrm{T} 1 \mathrm{with}$ the soaking time of $10 \mathrm{~h}$ (heating rate $5^{\circ} \mathrm{C} \min ^{-1}$ ). Representative microstructures of selected samples are given in Figure 2. They reveal an average grain size of $280 \mathrm{~nm}$ for the higher temperature regimes of sintering ( $\mathrm{T} 1$ and $\mathrm{T} 2$ above 1300 and $1200^{\circ} \mathrm{C}$, respectively), whilst finer 
microstructures were observed with an average grain size of less than $200 \mathrm{~nm}$ when lower sintering temperatures were used.

Table 2. Two-stage sintering conditions for zirconia tiles and corresponding average grain size and density.

\begin{tabular}{c|cccccc} 
Temperature T1/T2 / ${ }^{\circ} \mathrm{C}$ & $1400 / 1300$ & $1375 / 1275$ & $1350 / 1300$ & $1350 / 1250$ & $1300 / 1200$ & $1250 / 1150$ \\
\hline Time at T2 / hour & 5 & 5 & 10 & 10 & 5 & 1.5 \\
\hline Density / \% of TD & 98.3 & 98.2 & 98.6 & 98.5 & 96.5 & 95 \\
\hline Average grain size / nm & 280 & 280 & 280 & 270 & 190 & 130
\end{tabular}

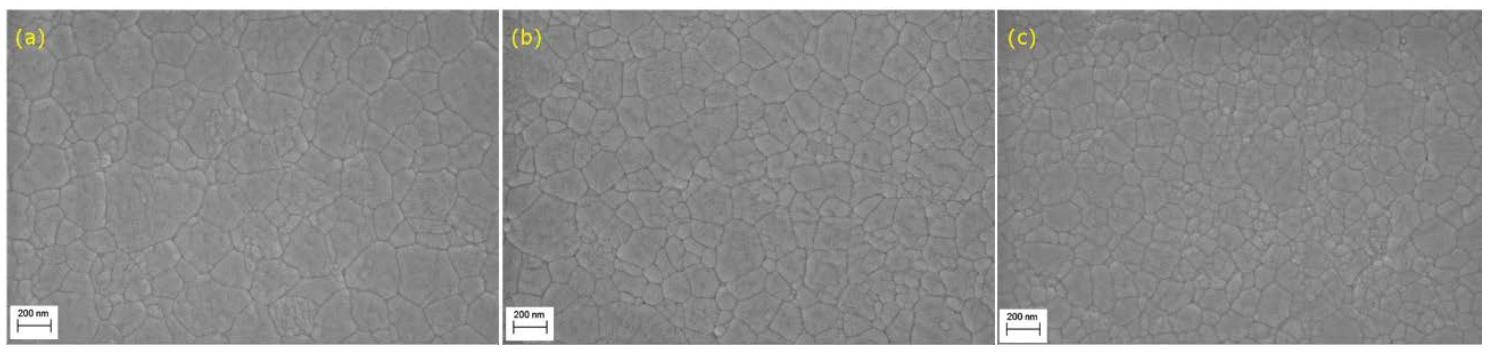

Figure 2. SEM micrographs of tile samples sintered at different conditions, T1/T2/time, Temperature is in ${ }^{\circ} \mathrm{C}$ and time in hours. (a) 1400/1300/5, average grain size $280 \mathrm{~nm}$, (b) $1375 / 1275 / 5$, average grain size 280 and (c) 1250/1150/1.5, average grain size $130 \mathrm{~nm}$.

Mechanical properties and slurry erosion performance - The hardness and indentation toughness of the zirconia samples were measured as $11.21 \pm 0.38 \mathrm{GPa}$ and $5.35 \pm 0.32$ MPa $\mathrm{m}^{1 / 2}$, respectively. The flexural strength was measured for the samples with similar sintered densities $(98.4 \pm 0.3 \%)$ and it was confirmed that it was $633 \pm 31 \mathrm{MPa}$, which is lower that the values typically reported for zirconia [12]. This is attributed to the lower 
sintered densities obtained. This was evident from the variations of flexural strength as a result of increase in the sintered density.

The initial indicator on the performance of different samples in the slurry erosion tests was the difference between the weight loss resulting from the removal of the material at the slurry jet impact point during the test. The weight loss of the samples after the erosion test is shown in Table 3. These results indicate that the zirconia sample outperformed the stellite-coated steel sample, which showed poor erosion resistance at $19 \mathrm{mg}$ weight loss as compared to that of the zirconia sample showing only $0.3 \mathrm{mg}$ weight loss. The performance of manufactured zirconia can be benchmarked with reported literature for alumina [10] and partially stabilised zirconia(PSZ) [7]. The slurry erosion test reported herein has higher flow rates, higher jet velocity and smaller sand size distribution as compared with the comparison literature (flow rate: $4.61 \mathrm{~min}^{-1}$, jet velocity: $7.3 \mathrm{~m} \mathrm{~s}^{-1}$, size distribution: $\left.600-850 \mu \mathrm{m}\right)$. Nonetheless, the weight loss of nanostructured zirconia after 90 minutes was only $0.3 \mathrm{mg}$, whilst alumina and PSZ showed weight loss values of $13.7 \mathrm{mg}$ and $1 \mathrm{mg} \mathrm{cm}^{-2}$ after 60 minutes of erosion testing, respectively $[7,10]$. Fang et al. $[7,10]$ observed no significant effect from the grain size on erosion properties of alumina (grain size of 5-6 $\mu \mathrm{m}$ ) whilst surface roughness was observed to play a major role due to the effect of surface defects in erosion performance of brittle ceramics. PSZ ceramics tested by Fang et al.[10] had a grain size of $0.5 \mu \mathrm{m}$ and this clearly resulted in tetragonal to monoclinic phase transformation. Thus, in comparison, the performance of the nanostructured zirconia was estimated to be at least 3 times better than PSZ and 36 times better than alumina. 
Table 3. Changes in the weight of the samples after slurry erosion test. Mass balance accuracy was $\pm \mathbf{0 . 0 2} \mathbf{m g}$ for measurements.

\begin{tabular}{lccc} 
Samples & Weight before / $\mathbf{g}$ & Weight after / g & Weight loss /mg \\
\hline Stellite-coated & 231.246 & 231.227 & 19 \\
Zirconia & 62.2917 & 62.2914 & 0.3 \\
\hline
\end{tabular}

In-depth surface profile analysis of the erosion craters on both stellite-coated samples and zirconia samples was performed using surface profilometry. Figure 3-(a) shows the surface profile of the stellite-coated sample after erosion. It confirms the formation of a ring on the surface, which is similar to what has been reported for stellite in the literature [8]. This behaviour is commonly seen in soft and ductile metallic materials which suffer more from the abrasion attack at lower angles, leaving the central stagnation point almost unaffected [9]. The line scan, Figure 3-(b), shows a typical W shape for the erosion scar with the maximum depth of the erosion crater measured at approx. $17 \mu \mathrm{m}$. The outer diameter of the ring was about $15 \mathrm{~mm}$, which is much larger than the diameter of the nozzle (6 mm). As mentioned earlier, the outer region of the crater beyond the $6 \mathrm{~mm}$ diameter area is formed mainly by abrasion at low impact angles due to flow distributions after impact $[7,18]$. The surface roughness of the stellite sample was measured as $0.4 \mu \mathrm{m}$ at the uneroded area and $0.45 \mu \mathrm{m}$ at the eroded ring. This showed that slurry erosion increased the surface roughness of stellite-coated sample by $\sim 0.05 \mu \mathrm{m}$.

Figure 4 shows the surface profile of the zirconia after erosion. As shown, the difference at the surface of the eroded and non-eroded area is subtle, which makes it difficult to obtain information as clearly as in the case of stellite sample, in fact the ring scar is 
hardly visible. The surface roughness of the zirconia sample was measured as $0.23 \mu \mathrm{m}$ at the uneroded area and $0.19 \mu \mathrm{m}$ at the eroded area.

The reduction in roughness as well as different scar profiles after erosion implies that a different mechanism was involved during the erosion of the zirconia samples as compared to that of the stellite-coated sample. This could be explained by comparing the mechanical properties of the samples and their corresponding resistances to erosion and abrasion; high hardness of the zirconia sample and the brittle nature of the wear scar as compared to more ductile behaviour observed for the stellite samples [10]. The mechanism of erosive wear depends on the type of material being eroded since it determines whether wear occurs by plastic deformation and/or brittle fracture.[19] Whilst ductile materials suffer wear due to plastic deformation, brittle materials such as ceramics and cermets undergo wear as a result of removal of material by the formation of cracks and the resulting grain ejection from the surface.[19,20] The formation of Wshaped wear scars in ductile materials are commonly seen under normal impact angle erosion conditions[7], as observed here for the stellite-coated sample. This is due to the fact that aggressive abrasion at lower angles damages the material significantly whilst at the stagnation point at the centre where the real impact angle is $90^{\circ}$ the material suffers less damage. In case of brittle ceramic materials, the formation of a U shape scar under slurry erosion conditions has been attributed to the brittle nature of the failure at the erosion crater.[8,10] In the case of large grain zirconia ceramics, any resulting phase transformation could also facilitate material removal due to the associated volume expansion and loss of mechanical properties. The superior hydrothermal ageing resistance of nanostructured zirconia prevents this mechanism of material removal and in turn leading to enhanced erosion resistance. 

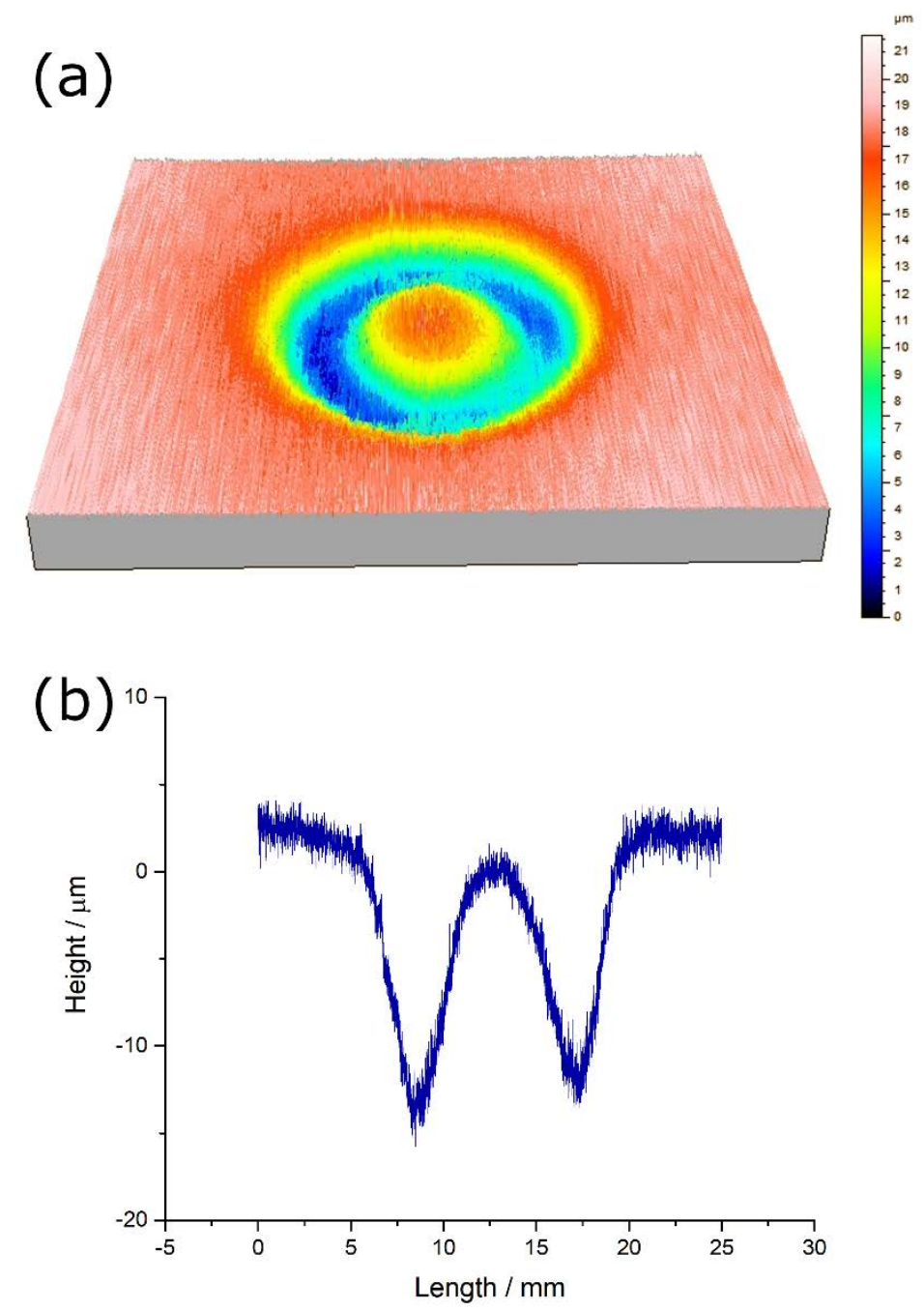

Figure 3. (a) Surface profile image of the stellite sample after erosion test. (b) Single line scanning surface profile of the stellite sample. The scan path is through the centre of the erosion crater. 
(a)

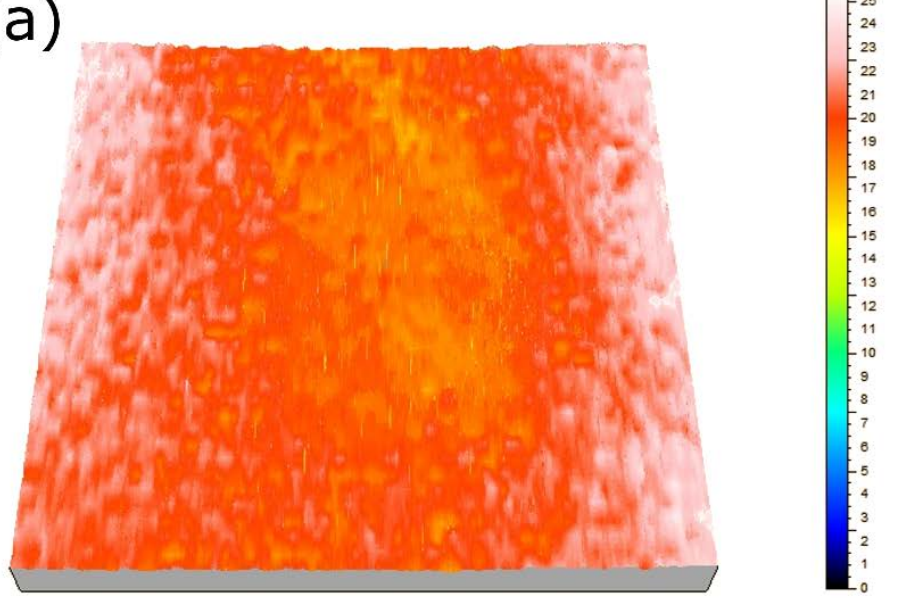

(b)

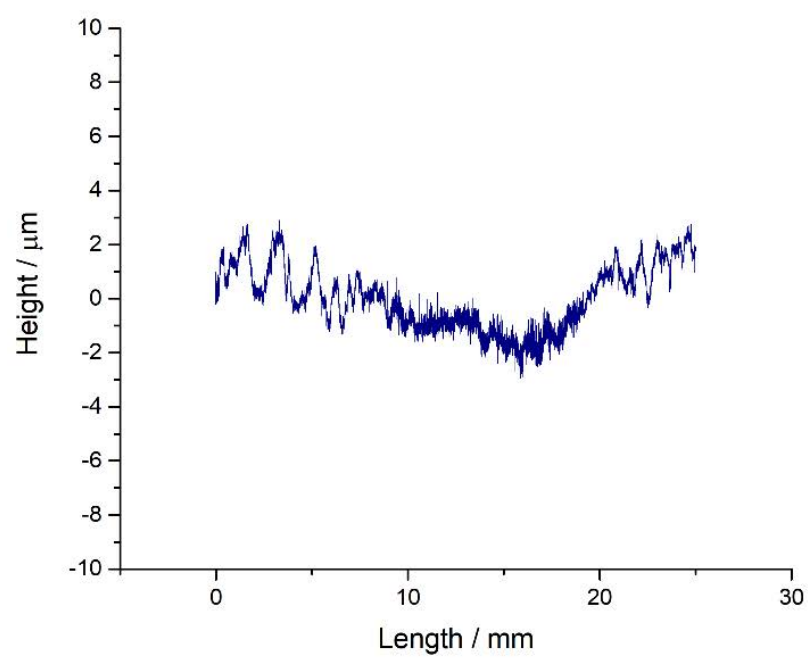

Figure 4. (a) Surface profile of the eroded area on the zirconia sample. (b) Single line scan of surface profile of the zirconia sample at the centre of crater. The eroded area is seen towards the centre of the line scan. 

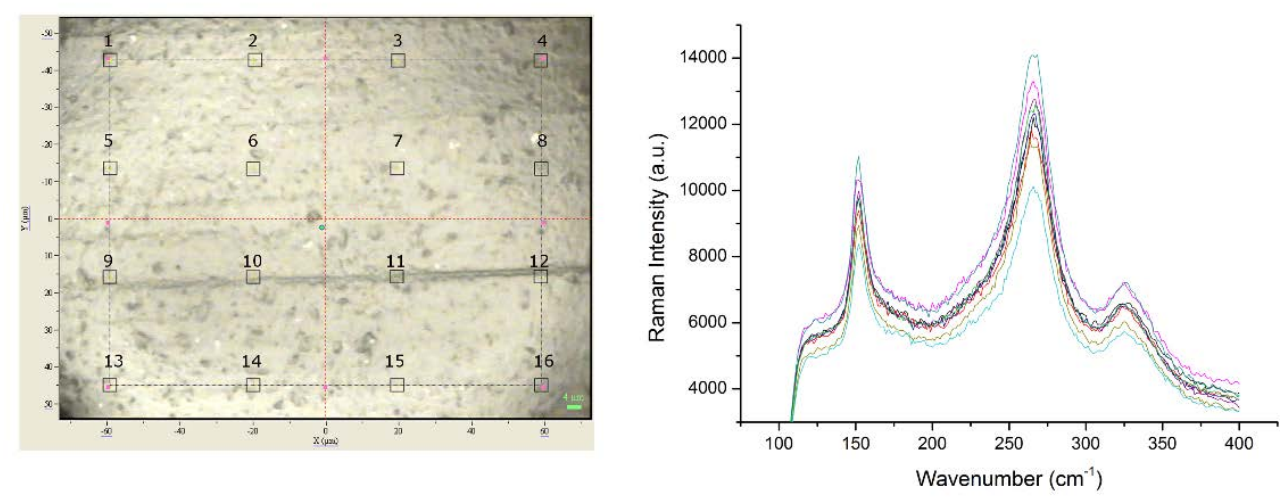

Figure 5. Raman spectra of ceramic samples at the eroded area after slurry erosion test. 16 points shown by $\square$ in the left image were scanned to map the surface of the erosion crater.

One of the major concerns for the use of zirconia ceramics in wear applications where moisture is involved [21], such as bio-implants and petrochemical valves, is hydrothermal degradation. Kobayashi et al. [11] was the first to report this ageing transformation. The suitability of zirconia for the application in moisture containing environments was further examined by Raman spectroscopy as a tool to distinguish monoclinic and tetragonal phases that could form at the surface of the zirconia.

Figure 5 shows the Raman spectra obtained for different points on the eroded area of the zirconia tile. As seen in Figure 5, no phase transformation could be identified in any of the points studied. Monoclinic peaks usually occur at $181 \mathrm{~cm}^{-1}$ and $192 \mathrm{~cm}^{-1}$ [12]. All spectra obtained showed typical Raman spectra for tetragonal zirconia and no peaks of monoclinic zirconia were observed. This confirmed that no tetragonal to monoclinic phase transformation occurred as a result of slurry impingement erosion experiments in these nanostructured zirconia ceramics. 
Erosion results showed that zirconia ceramic samples outperformed the stellite-coated steel samples; the material that is commonly used in petrochemical valves. Zirconia showed only $0.3 \mathrm{mg}$ weight loss, a nearly 60 fold improvement compared to stellite specimens under these test conditions, while no phase transformation was observed. These results are very encouraging and suggest that nanozirconia is a promising alternative for petrochemical valve components. However, it must be noted that the erosion tests were done at temperatures around $20^{\circ} \mathrm{C}$. However, the actual working temperature of valve components is around $90-100^{\circ} \mathrm{C}$. Therefore, further work is required to evaluate the performance of these materials at higher temperatures. It is also crucial to improve the sintered density of the final product, since mechanical properties such as flexural strength are significantly reduced by a low sintered density.

\section{Conclusions}

Zirconia-based ceramics are known to yield excellent mechanical properties and are used in a wide range of engineering applications from wear parts for the die drawing industry through to oxygen sensors and solid oxide fuel cells. One major limitation for these ceramics, however, is their lack of resistance to a process known as hydrothermal ageing. Internal trim components and wear parts for valves and pumps for use in the petrochemical industry are example products that need a hydrothermally resistant ceramic material. Our results showed that large enough nanostructured zirconia samples can be fabricated through optimising the manufacturing conditions. Further, suitable sintering conditions to yield dense zirconia samples with sintered densities of $>98 \%$ TD are identified. In order to evaluate the suitability of manufactured zirconia for valve 
component applications the parts were subjected to slurry erosion at room temperature. The nanozirconia showed a 60-fold improvement in terms of reduced weight loss compared to commonly used stellite-coated commercial stainless steel specimens under slurry erosion conditions. This confirmed that zirconia offers a significant advantage in applications where failure is mainly caused by erosion and that it has the potential to replace commonly used stainless steel.

\section{Acknowledgements}

Authors would like to thank EPSRC and Finance SouthEast for financial support (EPSRC Reference: EP/I500227/1). This work was carried out in close collaboration with MEL Chemicals, Dynamic Ceramic Ltd and Valve Solutions. Authors are also grateful for the help of Dr Yifei Zhang and the assistance received from Research Institute for Industry (RIfI, University of Southampton) and Loughborough Materials Characterisation Centre (LMCC) at Department of Materials, Loughborough University is also acknowledged.

\section{References}

[1] J. Binner, B. Vaidhyanathan, Processing of bulk nanostructured ceramics, J. Eur. Ceram. Soc. 28 (2008) 1329-1339. doi:10.1016/j.jeurceramsoc.2007.12.024.

[2] J. Binner, B. Vaidhyanathan, The art of the possible: pro- cessing nanostructured ceramics, Mater. World. 12 (2004) 30-32.

[3] H. Somekawa, T. Tanaka, H. Sasaki, K. Kita, A. Inoue, K. Higashi, Diffusion 
bonding in ultra fine-grained $\mathrm{Al}-\mathrm{Fe}$ alloy indicating high-strain-rate superplasticity, Acta Mater. 52 (2004) 1051-1059.

doi:10.1016/j.actamat.2003.10.036.

[4] C. Brahim, A. Ringuedé, M. Cassir, M. Putkonen, L. Niinistö, Electrical properties of thin yttria-stabilized zirconia overlayers produced by atomic layer deposition for solid oxide fuel cell applications, Appl. Surf. Sci. 253 (2007) 3962-3968. doi:10.1016/j.apsusc.2006.08.043.

[5] C. Xia, X. Lu, Y. Yan, T. Wang, Z. Zhang, S. Yang, Preparation of nanostructured Pt-YSZ composite and its application in oxygen potentiometric sensor, Appl. Surf. Sci. 257 (2011) 7952-7958. doi:10.1016/j.apsusc.2011.04.005.

[6] X. Liang, B. Lin, X. Han, S. Chen, Fractal analysis of engineering ceramics ground surface, Appl. Surf. Sci. 258 (2012) 6406-6415. doi:10.1016/j.apsusc.2012.03.050.

[7] Q. Fang, P.S. Sidky, M.G. Hocking, Erosion and corrosion of PSZ-zirconia and the t-m phase transformation, Wear. 233-235 (1999) 615-622. doi:10.1016/S0043-1648(99)00239-2.

[8] D. Cooper, F.A. Davis, R.J.K. Wood, Selection of wear resistant materials for the petrochemical industry, J. Phys. D. Appl. Phys. 25 (1992) A195-A204. doi:10.1088/0022-3727/25/1A/031.

[9] J. Knuuttila, S. Ahmaniemi, E. Leivo, P. Sorsa, P. Vuoristo, T. Mantyla, Wet abrasion and slurry erosion resistance of sealed oxide coatings, Proc. Int. Therm. Spray Conf. 1 (1998) 207-212. 
[10] Q. Fang, H. Xu, P.S. Sidky, M.G. Hocking, Erosion of ceramic materials by a sandrwater slurry jet, Wear. 224 (1999) 183-193.

[11] K. Kobayashi, H. Kuwajima, T. Masaki, Phase change and mechanical properties of ZrO2-Y2O3 solid electrolyte after ageing, Solid State Ionics. 3-4 (1981) 489493. doi:10.1016/0167-2738(81)90138-7.

[12] J. Binner, B. Vaidhyanathan, A. Paul, K. Annaporani, B. Raghupathy, Compositional effects in nanostructured yttria partially stabilized zirconia, Int. J. Appl. Ceram. Technol. 8 (2011) 766-782. doi:10.1111/j.17447402.2010.02503.x.

[13] I. Santacruz, K. Anapoorani, J. Binner, Preparation of high solids content nanozirconia suspensions, J. Am. Ceram. Soc. 91 (2008) 398-405. doi:10.1111/j.1551-2916.2007.02164.x.

[14] J.G.P. Binner, I. Santacruz, K. Anapoorani, Method for concentrating nanosuspensions, WO2006/136780A3, 2006.

[15] Y. Zhang, J. Binner, C. Rielly, B. Vaidhyanathan, Comparison of spray freeze dried nanozirconia granules using ultrasonication and twin-fluid atomisation, J. Eur. Ceram. Soc. 34 (2014) 1001-1008. doi:10.1016/j.jeurceramsoc.2013.10.033.

[16] K. Anapoorani, B. Vaidhyanathan, B. Raghupathy, J.G.P. Binner, Deformable Granule Production, EP2346951 (B1), 2016.

[17] B.A. Cottom, M.J. Mayo, Fracture toughness of nanocrystalline ZrO2-3mol\% y2o3determined by vickers indentation, Scr. Mater. 34 (1996) 809-814. doi:10.1016/1359-6462(95)00587-0. 
[18] M.-H. Wang, C. Huang, K. Nandakumar, P. Minev, J. Luo, S. Chiovelli, Computational fluid dynamics modelling and experimental study of erosion in slurry jet flows, Int. J. Comut. Fluid Dyn. 23 (2009) 155-172. doi:10.1080/10618560902744412.

[19] L. Urkovi, I. Kumi, K. Grilec, Solid particle erosion behaviour of high purity alumina ceramics, Ceram. Int. 37 (2010) 29-35. doi:10.1016/j.ceramint.2010.08.029.

[20] H.S. Grewal, A. Agrawal, H. Singh, Identifying Erosion Mechanism: A Novel Approach, Tribol. Lett. 51 (2013) 1-7. doi:10.1007/s11249-013-0156-4.

[21] A. Paul, B. Vaidhyanathan, J.G.P. Binner, Hydrothermal aging behavior of nanocrystalline Y-TZP ceramics, J. Am. Ceram. Soc. 94 (2011) 2146-2152. doi:10.1111/j.1551-2916.2010.04341.x.

\section{Figure Caption}

Figure 1. Pictures of samples as-pressed and after every processing step. (a) green compact after dry pressing at $110 \mathrm{MPa}$, green density of $42.5 \% \mathrm{TD}$, (b) green compact after isopressing at $200 \mathrm{MPa}$, green density of 49\%TD, (c) green compact after binder removal, green density of 52\%TD and (d) sintered sample with density of 98.2\%TD. 
Figure 2. SEM micrographs of tile samples sintered at different conditions, T1/T2/time, Temperature is in ${ }^{\circ} \mathrm{C}$ and time in hours. (a) 1400/1300/5, average grain size $280 \mathrm{~nm}$, (b) 1375/1275/5, average grain size 280 and (c) 1250/1150/1.5, average grain size $130 \mathrm{~nm}$.

Figure 3. (a) Surface profile image of the stellite sample after erosion test. (b) Single line scanning surface profile of the stellite sample. The scan path is through the centre of the erosion crater.

Figure 4. (a) Surface profile of the eroded area on the zirconia sample. (b) Single line scan of surface profile of the zirconia sample at the centre of crater. The eroded area is seen towards the centre of the line scan.

Figure 5. Raman spectra of ceramic samples at the eroded area after slurry erosion test. 16 points shown by $\square$ in the left image were scanned to map the surface of the erosion crater.

\section{Table Captions}

Table 1. Slurry jet impingement test conditions.

Table 2. Two-stage sintering conditions for zirconia tiles and corresponding average grain size and density.

Table 3. Changes in the weight of the samples after slurry erosion test. Mass balance accuracy was $\pm 0.02 \mathrm{mg}$ for measurements. 